\title{
Publishing ethics in Population Ecology
}

\author{
Kazunori Sato
}

Published online: 10 March 2015

(C) The Society of Population Ecology and Springer Japan 2015

A New 2-year term of editorial board has just started. Some Associate Editors and some editorial board members are replaced, and I myself remain as Editor-in-Chief. We would like to continue to publish a journal with highquality articles submitted by the readers. All article types of the submissions from you are welcome.

Now I believe that the quality of each scientific article is guaranteed by the several features: originality, accuracy, interest, significance, comprehensibility, and reproducibility. The peer-review process by the specialists for every submitted article should well function to authorize its quality. Unfortunately, however, the author's intentional or accidental "insincerity" sometimes goes through the severe eyes of reviewers. There may be various reasons for it, but we can partly blame it for the interdiscipline of the research because the specialist cannot often cover the wide range of topics or technics in it. I believe that the interdisciplinary studies strongly contribute to make progress of that field, and then Population Ecology should seriously tackle this problem.

I consider that a journal editor has some responsibility in judging the validity of the content of the articles. Thus we use CrossCheck powered by iThenticate to prevent the plagiarism in the submitted articles. This service provides us the information how much the sentences of the manuscript matches the database including a large amount of published research articles, conference proceedings and e-books, and highlights which part of the manuscript matches those database. We find it much useful to detect

\section{K. Sato $(\bowtie)$}

Department of Mathematical and Systems Engineering, Graduate School of Engineering, Shizuoka University, 5-1, Johoku 3-chome, Naka-ku, Hamamatsu 432-8561, Japan e-mail: sato@sys.eng.shizuoka.ac.jp the plagiarism, and indeed we have decided to reject a manuscript recognized as containing plagiarism, but sometimes asked the authors to paraphrase the sentences for innocent cases. So we would like to call on you to see "Ethical Responsibilities of Authors" on the web site before submitting your article (http://www.springer.com/ life+sciences/ecology/journal/10144).

\section{Special features}

In this issue we provide the special feature "Unravelling ecological networks: complexity-stability relations and diversity of interaction types" organized by Toshiyuki Namba. The five articles in this special feature are based on the presentations of the symposium in the annual meeting of the Society of Population Ecology in 2013: Network Structure and Dynamics of Ecological Communities. We will find that the special feature more focuses on the interaction strength and types of network. Namba reviews the 40 -year long history of studies on complexity-stability relationships in the preface, which is much substantial reading.

You can read another special feature and invited review articles within the next few issues. The proposal of a special feature is open to everybody, so please visit the web site of Population Ecology for more information.

\section{Editorial statistics}

During the year 2013, a total of 176 manuscripts were submitted from authors located in 37 different countries. Forty-seven $(26.7 \%)$ manuscripts originated from Europe, North America provided 32 (18.2\%), Asia (other than 
Japan) $46(26.1 \%)$, and Japan $20(11.4 \%)$. The rate of acceptance was $25.2 \%$ for non-invited papers. The rates of acceptance of manuscripts from Japan and North America were much higher than the average, and those from Oceania and Europe followed them.

The average time $( \pm \mathrm{SD})$ between the receipt of a manuscript and return to the first report to the authors was lengthened to 45.2 days $( \pm 35.6)$ from 42.5 days $( \pm 31.7)$ in 2012 and 38.8 days $( \pm 32.3)$ in 2011. The first round of reviews was completed within 60 days for 120 manuscripts $(68.2 \%)$, while the number of manuscripts for which the first round of reviews was finished within 90 days was 157 $(89.2 \%)$. Seventy-one manuscripts $(40.3 \%)$ were rejected by the editors before being sent to reviewers. We appreciate your cooperation to review the submitted articles to Population Ecology, and would like you to continue to help us.

\section{Photos on the cover page}

Two photos were selected from articles published in 2013 and the other two were selected from the previous volume published in 2014.

The photo on upper left shows the capture of a pea aphid (Acyrthosiphon pisum) by a ladybeetle (Harmonia axyridis). This predator-prey interaction is sensitive to temperature in complex ways. Abbott et al. (2014) built a model of this interaction to study possible effect of climate change on aphid population dynamics.

Newly hatched little tern (Sternula albifrons) chicks in the Port of Oulu, Finland (upper right). Pakanen et al. (2014) found little tern breeding success to be higher in artificial habitat than in natural beach habitat. Modeled parameter spaces for population growth rates indicated the potential to sustain stable populations is good in artificial habitats but lower in natural habitats.

In summer, the cave salamander Hydromantes strinatii (lower left) moves to underground environments, where it finds suitable fresh and humid conditions. However, different age classes select contrasting microhabitats: juveniles prefer superficial sectors, where microhabitat is suboptimal but there is more food, while adults prefer the deepest sectors, where abiotic conditions are most suitable (Ficetola et al. 2013).

The worldwide over-exploitation of baleen whales (suborder Mysticeti) in past centuries resulted in one of the largest population dynamic experiments on Earth. Witting (2013) showed that the population recovery of seven species (including the humpback whale Megaptera novaeangliae, lower right) is driven by a selection delayed acceleration of the growth rate.

\section{References}

Abbott K, Harmon JP, Fabina NS (2014) The challenge of predicting temperature effects on short-term predator-prey dynamics. Popul Ecol 56:375-392

Ficetola GF, Pennati R, Manenti R (2013) Spatial segregation among age classes in cave salamanders: habitat selection or social interactions? Popul Ecol 55:217-226

Pakanen V-M, Hongell H, Aikio S, Koivula K (2014) Little tern breeding success in artificial and natural habitats: modelling population growth under uncertain vital rates. Popul Ecol 56:581-591

Witting L (2013) Selection-delayed population dynamics in baleen whales and beyond. Popul Ecol 55:377-401 